\title{
High Concentration of Heat pumps in Suburban Areas and Reduction of Their Impact on the Electricity Network
}

\author{
Olaf van Pruissen and René Kamphuis, Member, IEEE
}

\begin{abstract}
One of the challenges of the near future for a more renewable Dutch electricity infrastructure is the embedding of high concentrations of heat pumps in currently built domestic residences. In the Dutch situation demand of electricity occurs simultaneously with demand of heat, high electricity peak loads in the low voltage network are expected. This study focuses on domestic residences with high peak loads at substations when heating is provided merely by heat pumps with additional electric resistance heating. Two scenarios are studied: the event of a black start in the electricity system and high electricity demand on a day with a very low outdoor temperature. The simulation is performed with agents representing up to 100 dwellings based on Multiagent control by means of the PowerMatcher concept. In the PowerMatcher concept software agents are used as representatives of the power producing and/or consuming installations. The results demonstrate significant peak load reduction can be achieved at the expense of only a small decrease of comfort.

The cost reduction calculation of the electricity network using Multiagent systems is presented. An estimation of this reduction, which is very location specific, includes the substation, the low voltage network, the transmission station and the medium voltage transport network.
\end{abstract}

Index Terms-Multiagent systems, Autonomous agents, Smart grids, Power distribution faults, Power demand, Power supplies, Substations, Heating, Heat pumps, Computer Simulation.

\section{NOMENCLATURE}

$\begin{array}{lll}\text { CHP } & - \text { Combined Heat and Power } \\ \text { COP } & - \text { Coefficient Of Performance } \\ \text { DSM } & - \text { Demand Side Management } \\ \text { DSO } & - \text { Distribution System Operator } \\ \text { ECN } & - \text { Energy research Centre of the Netherlands } \\ \text { EPC } & - \text { Energy Performance Coefficient } \\ \text { LV } & - \text { Low Voltage } \\ \text { MAS } & - \text { Multi Agent System } \\ \text { MV } & - \text { Medium Voltage } \\ \text { SDM } & - \text { Supply and Demand Matching } \\ \text { VPP } & - \text { Virtual Power Plant }\end{array}$

This work was supported in part by Agentschap NL under contract ISO 74001.

O. P. van Pruissen, I.G. Kamphuis are with the unit Efficiency \& Infrastructure, Energy Research Centre Netherlands, Westerduinweg 3, PO Box 11755 ZG Petten, The Netherlands (e-mail: \{vanpruissen, kamphuis\}@ecn.nl).

\section{INTRODUCTION}

$\mathrm{T}$ HE application of small renewable energy generators in households as part of the infrastructure in residential areas is increasing. The mode of implementation can have significant impact on electricity and its supply. The distribution capacity that is required may in some cases be much larger than usual in residential areas. Thus, important assets of electricity may be implemented considerable larger or heavier than usual with higher cost.

One of the possible variations in this respect is a residential area with heat pumps and electric resistance heating. Such a configuration has the advantage that no gas infrastructure needs to be built, allowing the construction cost to be avoided. For developers who have to meet the legal requirements regarding sustainability, this architecture is financially advantageous. The reason is that the building has sufficient home insulation with relatively little cost thereby for the promoter, with the so called EPC environmental value of the homes through the use of heat pumps satisfying the current standards.

Although the houses are well insulated, it is expected that, on cold days, which may occur on the average only once or twice a year, the power of the heat pump is insufficient to raise the temperature in the dwelling fast enough for user comfort. For this reason as a back-up electric resistance heating is present. As the power of the heat pump is typically $2.2 \mathrm{~kW}$ and the power of the electric resistance heating is $6 \mathrm{~kW}$, the total peak power may become much larger than the typical power of $1.1 \mathrm{kVA}$, available at the distribution level for a Dutch household.

In 2008 Dutch network companies were suddenly confronted with development plans that envisaged suburban areas where all dwellings are heated by heat pumps and electric resistance heating. Simultaneous operation of electric equipment on a household level does occur, but to a far lesser extent than with heating devices. As both the power of the heating devices and the simultaneity for heating is considerably larger than is generally the case, Distribution System Operators (DSO) calculated that the maximum simultaneous electricity demand of power would become much larger than in usual networks. By law they have the duty to wire all houses. So the local substation, which typically serves 124 similarly accomplished houses, needs either to be 
redesigned for a much larger peak load or the number of stations increased, thereby raising costs and negatively influencing lifetime expectancy of the components. They calculated that about 6 times more substations are needed that commonly in residential areas, much thicker Low Voltage (LV) distribution cables and an extra Medium Voltage (MV) transmission line may be needed as well. They figured out that the extra cost for the electricity supply necessary for new housing estates would become very high and hard to explain to society. They also wondered what the impact would be on the available electricity infrastructure when heat pumps are about to penetrate in not modern built housing areas. They foresee i.e. the need to replace LV cables by thicker ones. This comes down to activities such as digging in the ground in an existing road and accommodation infrastructure, making the cost very high.

Network companies facing these problems have wondered whether smart grid solutions can attribute to their design and maintenance problems by decreasing peak loads. During a field test with micro-CHP's, coordination of micro-CHPs using the PowerMatcher has shown this ability [8].

They described two scenarios which would challenge a possible solution. One is the situation of a very cold day, the other is the situation where a blackout has occurred on a cold day, all the houses have cooled down and where at the blackstart all the houses demand a large amount of heat.

This is why software agents were designed and built for this case and used in a simulation to investigate the overall electric behavior and explore the possibilities of smart grid solutions based on the market algorithms the PowerMatcher employs [9].

This study describes the results obtained with simulations that are tailored to a specific neighborhood: Hoogdalem at Gorinchem in the Netherlands. In this residential area heat pumps are connected to an aquifer. Heat pumps connected to energy storage underground are currently regarded as a most comfortable and efficient system for heating and cooling. In comparison to standard technologies heat pumps offer a competitive level of comfort, reduced level of noise, lower emission of greenhouse gases and acceptable safety for the environment [2], [3], [4].

One final remark addresses the opportunity of such a residential area equipped with a large number of heat pumps to be used as a Virtual Power Plant (VPP) for the reduction of imbalance [10]. In daily operation a certain shift of the heating of dwellings with ground floor heating is possible without infringement of user comfort. This aggregated demand of power provides sufficient flexibility available for the electricity network to be used as a source for benefiting the reduction of imbalance. Research focusing on this business case is currently in progress.

\section{MULTIAGENT SYSTEMS AND ELECTRONIC MARKETS}

The multi-agent approach localizes and confines data, processing and controlling in a bottom-up fashion, without an omniscient top-level. In comfort control this has several benefits, such as 1) the generic description of installations 2) plug and play behavior of appliances 3) adaptation to the circumstances instead of predefined behavior and 4) no need for complex flow diagrams. For coordination of devices to match supply and demand in an electricity network, there has already been developed and tested a successful technology, 'the PowerMatcher'.

The PowerMatcher is a general purpose coordination mechanism for balancing supply and demand in electricity network [5]. This technique implements supply and demand matching (SDM) using a multi-agent systems and marketbased control approach. SDM is concerned with optimally using the possibilities of electricity producing and consuming devices in order to alter their operation in order to increase the over-all match between electricity production and consumption. Within a PowerMatcher cluster, the agents are organized into a logical tree. In this study the leaves of this tree are a number of agents representing a device. This agent tries to operate the process it is associated with in an economical optimal way.

The interactions of individual agents in multi-agent systems can be made more efficient by using electronic markets, which provide a framework for distributed decision making based on microeconomics. Microeconomics is a branch of economics that studies how economic agents make decisions to allocate limited resources, typically in markets where goods and services are being sold or bought. Whereas economists use microeconomic theory to model phenomena observed in the real world, computer scientists use the same theory to let distributed software systems behave in a desired way. Market mechanisms provide a way to incentivize parties (in this case software agents), that are not under control of a central authority, to behave in a certain way $[1,7]$. A microeconomic theory commonly used in MAS is that of general equilibrium.

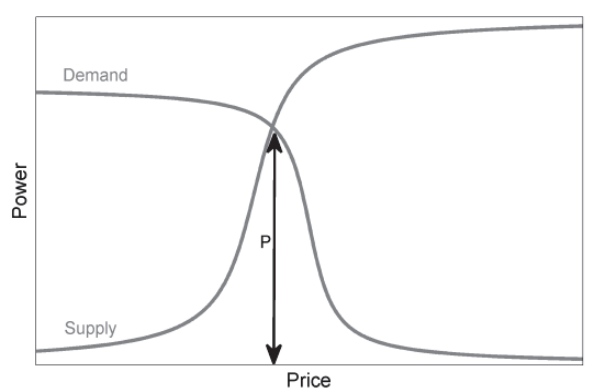

Fig. 1. Matching supply by representation of the bidding curves ( $\mathrm{P}$ is the exchanged power).

In general equilibrium markets all agents respond to the same price that is determined by searching for a price that balances all demand and supply in the system. An agent on such a market coordinates its actions with all other agents by buying or selling a commodity, here electricity. In order to do so, the agent communicates its latest bid (see below) to a socalled auctioneer and receives price updates from the auctioneer. The bids express to what extent an agent is willing to pay for or receive a certain amount of power; a request is converted to an adaptive price signal. As bids are constructed in a process of weighing the profits versus the costs, thus they 
represent the utility function of the agent. The bids are ordinary demand functions $d(p)$, stating the amount of electricity the agents wishes to consume (or produce) at a price $p$. After collecting all bids, the auctioneer searches for the equilibrium price $\mathrm{p}^{*}$, i.e., the price that clears the market:

$$
\sum_{a=1}^{N} d_{a}\left(p^{*}\right)=0
$$

where $\mathrm{N}$ is the number of participating agents and $d_{a}(p)$, the demand function of agent a. The price is broadcast to all agents. Individual agents can determine their allocated production or consumption from this price and their own bid.

Figure 1 is a schematically example of how the electricity market will try to balance demand and supply, taking into account the bids of all agents. The communication between device agents and an auctioneer is very limited. The only information that is exchanged between the agents and the auctioneer are the bids and the price. The auctioneer communicates the price back whenever there is a significant change. The PowerMatcher system thus optimally uses the possibilities of power producing and consuming devices to alter their operation in order to increase the over-all match between supply and demand real-time. Intelligent agents can also be utilized in the planning and operation of decentralized supply and demand [11]. Part of the PowerMatcher is the possibility of the presence of an objective agent. Such an objective agent generally implements an externally imposed objective. The objective agent interfaces to the business logic behind the specific application. It has been shown that a PowerMatcher cluster acts very well as a virtual power plant control (VPP) [8].

\section{POWERMATCHER MODEL}

For the residential area of Hoogdalem a PowerMatcher configuration for the LV grid was designed which represents the heating devices for 100 houses and the substation (distribution station) as shown in fig. 2.

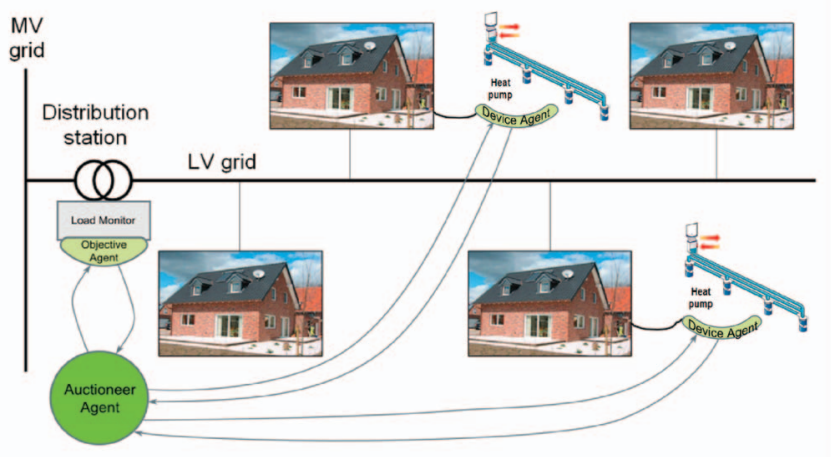

Fig. 2. Residential area with heat pumps and electric resistance heating in a distributed network according to the PowerMatcher configuration.

Two software agents were developed i.e. a heat pump device agent and a substation agent implemented as an objective agent. The auctioneer agent receives bids from each device agent and the substation agent. The heat pump device agent represents a dwelling with a heat pump and auxiliary electric heating. A building model is incorporated in the agent, enabling the calculation of the indoor temperature. During a black out period some houses might become much colder than others. From a human physiology point of view, one might argue that those homes should be heated first as comfort sharply decreases with decreasing temperature [6]. The algorithm employed by the heat pump agents ensures that the coldest houses are heated first and the temperature difference between the houses is levelled out quite soon.

Bid curves heat pumps at different $\Delta T$

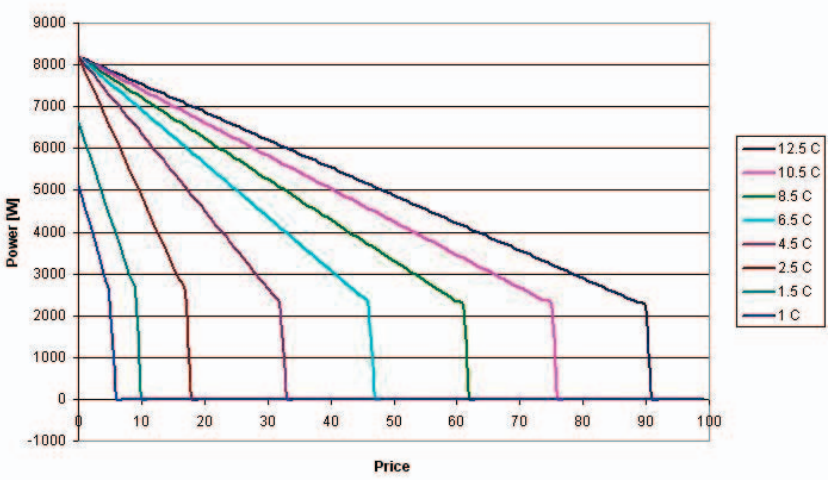

Fig. 3. A schematic representation of the bid curves issued by the heat pump agent as a function of the temperature difference between the indoor temperature and the temperature set point.

Fig. 3 shows a schematic representation of the bid curves of the heat pump depending on the temperature difference between the indoor temperature and the temperature set point. As can be seen the willingness of the heat pump agent to pay for power for heating purposes increases at increasing temperature difference.

The step of a power of $2200 \mathrm{~W}$ at the right hand of the bid curve corresponds to the capacity of the heat pump. This implicates that at first allocation, enough power is available to turn the heat pump on, in preference to the electric resistance heating. This is very beneficial to the overall system energy efficiency, as the coefficient of performance (COP) of a heat pump $(\mathrm{COP} \approx 3-4)$ is better than that of electric resistance heating $(\mathrm{COP} \approx 0.95)$. To further secure good performance, it is ensured that the heat pump is turned on for a longer time span, e.g. 30 minutes. At lower prices more power is available, which is allocated to the electric resistance heating.

A building model is incorporated in the agent, enabling the calculation of the indoor temperature. The power can be determined which is allocated to both devices and the corresponding heat can be calculated which is released to the house, as well as the heat loss through windows, walls etc., depending on the outdoor temperature. The resulting room temperature is calculated after a certain time period, in a simulation typically 2 minutes. The set point value of the indoor temperature depends on the presence and preferences of the habitant, which are resolved based on random parameters. A certain bandwidth around the indoor temperature is employed, preventing the device from switching on and off too often.

The substation agent's objective is to prevent the supply of electricity from becoming so large, i.e. increasing above a 
certain maximum load, above which the likelihood of thermal overload of the transformer in the substation is too large. In practice a representative current or voltage is surveyed and once this exceeds a certain cut-off value $\mathrm{L}_{\text {cut-off }}$, which is smaller but close to the maximum $\mathrm{L}_{\text {maximum }}$ a bid curve is send, preventing the device agents from getting their full allocation . This translates for the PowerMatcher to a certain price increase of electricity, so that less electricity is supplied by the substation, but still within a region between $\mathrm{L}_{\text {cutoff }}$ and $\mathrm{L}_{\text {maximum. }}$ In a simulation no current or voltage can be determined. However it is possible to infer the total power passing through the substation. In fact this the power allocated by all heat pump dwelling agents. This is accomplished through the possibility of an agent in the PowerMatcher system to ask the auctioneer to send the aggregated bid and given the price, determine the load. When the load becomes equal to $\mathrm{L}_{\text {maximum, }}$ the load agent is designed in such a way that the price will become $\mathrm{P}_{\text {maximum }}$ (In fig. $3 \mathrm{P}_{\text {maximum }}=100$ ). The bid curve of the objective load agent is then almost zero at all prices. At loads below $\mathrm{L}_{\text {cutoff }}$ the price is allowed to become $\mathrm{P}_{\text {minimum }}$, the bid curve of the load agent in this case has a high value of power at all prices. In the region between $\mathrm{L}_{\text {cutoff }}$ and $\mathrm{L}_{\text {maximum }}$ the bid curve is near zero for low prices and has a high value above a certain load price, which is a parameter that is calculated by the load agent.

\section{RESULTS}

Simulations were performed with 100 dwellings and varying maximum load of the substation. Outdoor temperatures used in the simulation are actual recorded temperatures in 2000. Black start conditions are simulated when outdoor temperatures are as low as $0{ }^{\circ} \mathrm{C}$.

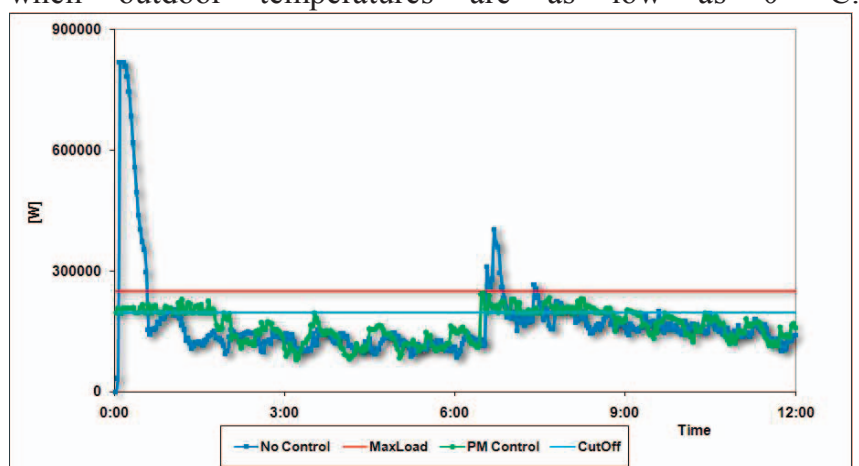

Fig. 4. Load at a substation for 100 dwellings after a black start and on a cold morning with and without PowerMatcher control. Maximum permitted load is $30 \%$ of maximum load without control.

Fig. 4 shows the total load of a substation on a cold winter's morning with and without PowerMatcher control. The left part shows the power after a black start. In the uncontrolled situation a very high peak demand occurs after a black start. At about 6:30h another peak demand occurs due to households demanding heat for the comfort of their inhabitants as they wake up. With the PowerMatcher control the load never exceeds the maximum permitted load $\mathrm{L}_{\text {maximum }}$ which is $30 \%$ of the maximum load which would occur without PowerMatcher control.
Several other simulations were performed at a different number of houses (still less than 100) and at varying $\mathrm{L}_{\text {maximum }}$, i.e. percentages of the maximum load of the substation. Another example is shown in fig. 5 for 4 houses after a blackstart.

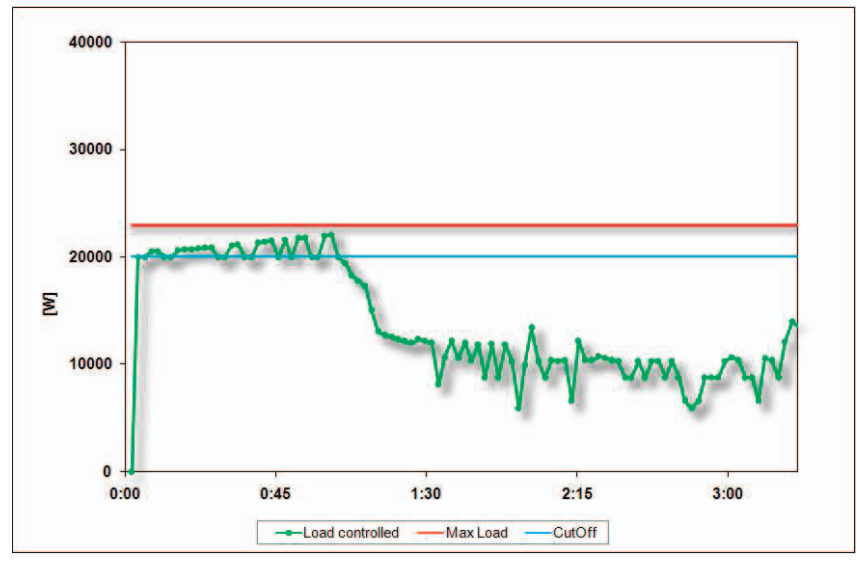

Fig. 5. Peak load reduction after a black start. The simulation comprises 4 dwellings and a transformer station operating at a maximum permitted load which is $70 \%$ of maximum load without control.

It was observed that the power at the substation did not exceed the maximum permitted load $\mathrm{L}_{\text {maximum }}$ at substation reduction percentages up to $87 \%$.

The data of Fig. 4 can be transformed into a load duration curve, which is shown in Fig. 6. The large peak at the left of the diagram without control has disappeared in the controlled situation. Note that the surface below both curves are comparable, meaning that control hardly affects the amount of energy (electricity) supplied to the dwellings.

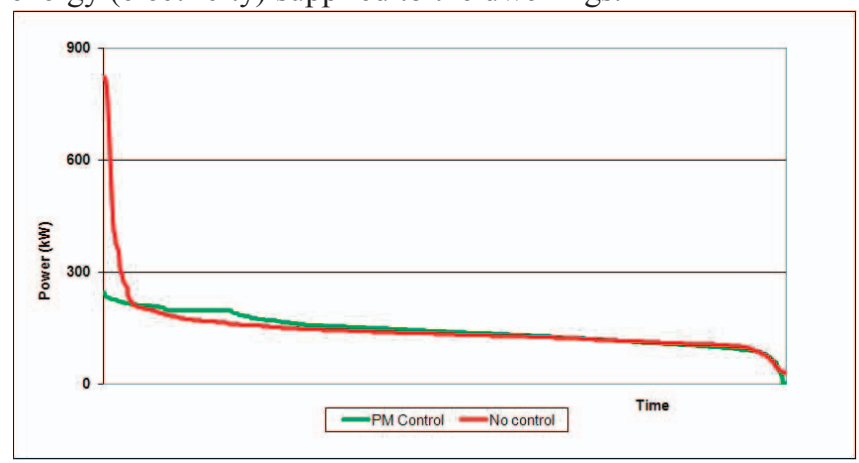

Fig. 6. Load duration curve for substation with 100 dwellings with and without PowerMatcher control. Maximum permitted load is $30 \%$ of maximum load without control.

Since after a black start and at a cold morning in a PowerMatcher controlled situation less electricity is allocated for the heating devices of the household, this means that initially less energy is available for heating the dwelling. So, the increase of the indoor temperature in time is in the controlled situation not as fast as in the uncontrolled situation. In the uncontrolled situation a certain delay time is applicable before the scored indoor temperature equals the set point. In a controlled situation the inhabitants have to wait longer for this event. At a waiting time equal to the normal delay time, the indoor temperature will be different from and lower than the 
set point. This can be considered as a decline of user comfort. To assess the extent of infringement with respect to user comfort the difference between the indoor temperature and the set point temperature of an average household was deduced from several simulations, as a function of the reduction of the maximum capacity of the substation.

The actual delay time in the uncontrolled situation may vary from 45 minutes to 12 hours, depending on the insulation of the house, the floor mass, the building mass and the upper floor thickness where the heating pipes are present. To achieve a general comparison irrespective of the actual delay time, the delay time for the uncontrolled situation was assumed to be equal to 1 . So, supposing an actual delay time of 1 hour corresponding to a value of 1 , a waiting time equals to 2 corresponds to a waiting time of 2 hours.

Fig. 7 shows the results for two waiting times, i.e. 1.5 times and 3 times the normal delay time. As an example, from this figure it can be inferred that at a reduction of $70 \%$ of the substation, indoor temperature of an average household has reached the set point temperature after a waiting time 3 times the normal delay time and is lagging behind $1^{\circ} \mathrm{C}$ after 1.5 the normal delay time.

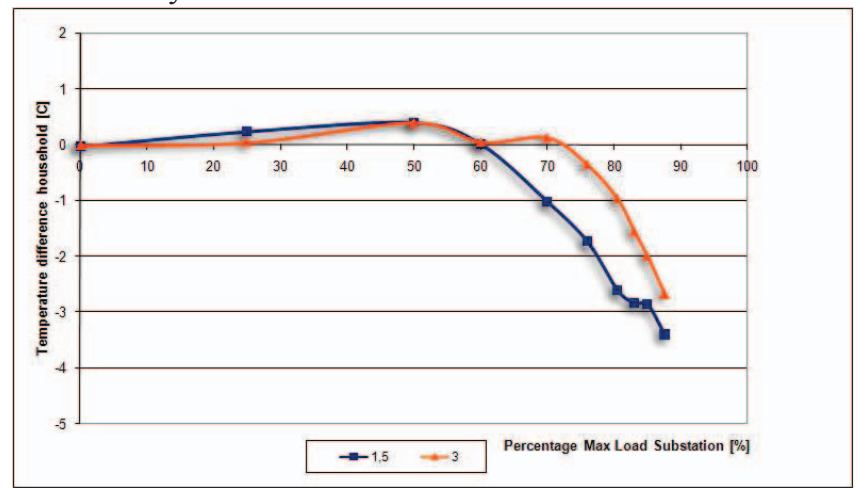

Fig. 7. The difference between the desired and the realized indoor temperature for an average dwelling after two different waiting time periods as a function of the reduction percentage of the maximum capacity. The values are extracted from several simulations of 100 dwellings and a substation after a black start.

Which temperature difference after which waiting time finally is acceptable, should be judged by a third, external party. Within contemporary regulation a DSO is not competent for this. Notice that this kind of event only occurs on just a few days a year.

\section{COST REDUCTION}

Applying PowerMatcher technology for demand response in a residential area with heat pumps, costs can be reduced. An important thing to notice is that this reduction depends very much on the specific local network topology, occupation patterns (i.e. residential, commercial and services) and the presence of industry activities in the vicinity. If commercial or industrial activities are already present, generally the infrastructure of the transmission MV network suffices (as well as for the high voltage network). One of course has to take into account that reserve capacity can only once been given away and that yet at another increase of load, next extension capacity should be accomplished. Whether extra capacity in the higher situated networks is necessary, further depends on the number of houses, the power of the heat pumps, the electric resistance heating as well as provisions taken for the presence of other electricity consuming equipment. Another example is a resort with heat pumps at a remote location such as a Frisian island, yet it may also be an area located as such that underneath a river an extra pipeline network needs to be installed. In such occasions cost will be much higher than in the elaborate example below. Nevertheless in all cases the incurrent cost will include extra substations, cables of the LV network underground, the distribution part of the local MV network and the MV/LV transforming station. The cost for the laying of the cables underground are mainly determined by the excavations. If digging is necessary, extra costs for the cables are fairly negligible.

As an example for cost reduction the estate of Hoogdalem at Gorinchem has been chosen. Apart from the costs arising from the adjustment of the LV network, at this location an extra track for the MV transmission network was installed.

For the calculation a number of premises were made. A $50 \%$ reduction of the maximum capacity of the substation by applying smart control was assumed. The extra waiting time for an inhabitant before the desired indoor temperature is reached, is relative small. Which delay time finally is acceptable, should be judged by a third, external party. The reduction of $50 \%$ is considered as a conservative assumption. Another assumption is that no extra transmission track is required thanks this reduction.

For this calculation key figures are assumed given by the Dutch DSO (Stedin). These key figures are shown in table I:

TABLE I

KEY FIGURES FOR CALCUTION OF THE COST REDUCTION BY APPLYING SMART CONTROL FO R SUBSTATIONS

\begin{tabular}{|c|c|}
\hline Extension of the LV network & 40 euro each meter \\
\hline $\begin{array}{c}\text { Extension of the MV } \\
\text { distribution network }\end{array}$ & 85 euro/meter \\
\hline $\begin{array}{c}\text { Extension of the MV } \\
\text { transmission network }\end{array}$ & $\begin{array}{c}300 \text { euro/meter (civil } \\
\text { importation work such as a } \\
\text { crossing of a river by a canal } \\
\text { or drilling under highways) }\end{array}$ \\
\hline Substation 630 kVA & 20.000 euro \\
\hline MV/LV Transformer station & 5 euros/avoided KVA \\
\hline
\end{tabular}

Given these assumptions, first the moderation in cost is calculated valid for all locations.

TABLE II

LEAST MODERATION OF COST VALID FOR ALL LOCATIONS

\begin{tabular}{|c|c|}
\hline Cables of the LV network & Negligible \\
\hline Substations & 220.000 euro \\
\hline MV/LV Transformer station & 35.000 euro \\
\hline
\end{tabular}


The moderation of cost for the LV network in the case of Hoogdalem is neglected, as this concerns mainly excavation work which has to be accomplished anyhow. In the residential area of Hoogdalem 1400 dwellings are present, with 2 substations of $630 \mathrm{kVA}$ each 124 dwellings. In total 22 substations are planned. At a reduction of $50 \%$ this means 11 substations less to be built. In total $6930 \mathrm{kVA}$ is avoided. This means that irrespective the location, costs of about 250.000 euro can be avoided.

In the case of Hoogdalem also the cost of the construction of a third track can be avoided. As the length of this track is about 4 kilometer, the reduction of cost amounts to a total of 1.200 .000 euro.

Aforementioned example demonstrates the dependence of cost reduction on location. Sometimes an extra investment of 250.000 euro can be avoided, sometimes this concerns an investment of 1.450 .000 euro. On specific locations such as a Frisian island the reduction of cost can be huge.

As the construction of 11 substations can be avoided extra parcels or public space is released. The extension of available space also includes an improvement of the financial statement of parties concerned.

\section{CONCLUSIONS}

From the simulations it can be concluded that using Multiagent technology for demand response it is possible to reduce the size of the substation without exceeding its maximum capacity. Good energy efficiency is achieved by giving a preference to the heat pump, which has a better COP than the electric resistance heating, once power is allocated to the heating devices. This is further ensured by a certain minimum time span the heat pump is turned on. It is possible to quantify the degree of user infringement as a function of the reduction of the substation, occurring on just a few days. A third party can deduce the preferred reduction of the substation from a graph showing the temperature difference between the indoor temperature scored and the set point temperature versus the percentage of maximum load reduction of the substation. The cost reduction is location specific and depends on the extension of the LV network, extension of the MV distribution network, extension of the MV transmission network, the number of substations avoided and reduction of the MV/LV transformer station. The cost reduction generally varies from 250.000 Euro to 1.450.000 Euro.

\section{ACKNOWLEDGMENT}

This work is partly financial supported by Agentschap NL, in the Smartproofs project, with project partners Stedin, Alliander, Enexis, TNO, Energy Valley and Humiq.

The authors wish to thank Theo Meeks of Stedin, DSO, in cooperating and reviewing the cost reduction calculation.

\section{REFERENCES}

\section{Periodicals:}

[1] Dash, R.K., Parker, D.C., Jennings, N.R.: Computational mechanism design: A call to arms. IEEE Intelligent systems 18(6), pp. 40--57. Washington, 2003.
[2] H. Esen, M. Inali, A. Sengur, M. Esen, "Performance prediction of a ground-coupled heat pump system using artificial neural networks", Expert systems with applications 35, pp1940-1948, 2008.

[3] A.M. Omer, "Ground source heat pump systems and applications", Renewable and Sustainable Energy Reviews 12, pp344-371, 2008

[4] J.D. Spitler, "Ground-source heat pump system research - past, present and future", HVAC and Research 11, 2, 2005

Books:

[5] J.K. Kok, M.J.J. Scheepers, I.G. Kamphuis, "Intelligence in electricity networks for embedding renewables and distributed generation," in Intelligent Infrastructures, R.R. Negenborn, Z. Lukszo, J. Hellendoorn (Eds) Springer, Dordrecht Heidelberg London New York, 2010, pp 179-209 .

[6] P.O. Fanger, Thermal comfort analysis and applications in environmental engineering, McGrawHill, London, New York, ISDN 007-0199154, 1970.

[7] Sandholm, T.W.: Distributional rational decision making. In: Multiagent Systems: A Modern Approach to Distributed Artificial Intelligence, pp201--258, The MIT Press, Cambridge Massachusetts, 1999.

\section{Papers from Conference Proceedings (Published):}

[8] B. Roossien, M. Hommelberg, C.J. Warmer, J.K. Kok and J.W. Turkstra, "Virtual power plant field experiment using 10 micro-CHP units at consumer premises" CIRED SmartGrids Seminar '08, paper 86.

[9] J.K. Kok, C.J. Warmer, I.G. Kamphuis, "PowerMatcher : multiagent control in the electricity infrastructure", Fourth international conference on Autonomous Agents \& Multi-Agent Systems, AAMAS ’05, July 25-29, 2005, Utrecht, Netherlands.

[10] C.J. Warmer, M.P.F. Hopmmelberg, I.G. Kamphuis, Z. Derszi and J.K. Kok, "A field test for real-time reduction of intermittent imbalance with the PowerMatcher", Sixth International Workshop on Large-Scale Integration of Wind Power, Delft, 2006.

[11] H.F. Wedde, S. Lehnhoff, E.Handschin, O.Krause, "A distributed realtime multi-agent system for decentralized management of electric power", $18^{\text {th }}$ Euromicro Conference on Real-Time Systems, Dresden, Germany, July 2006.

\section{BIOGRAPHIES}

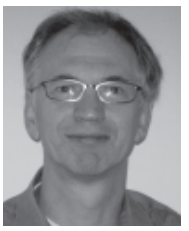

Olaf van Pruissen holds a $\mathrm{PhD}$ in chemical physics. His employment experience includes the University of Utrecht, the Technical University of Delft, TNO and ECN, where he worked on topics as urban air pollution, diesel soot catalysts and smart grids.

He is currently employed at the department Efficiency \& Infrastructure of the Energy research Centre of the Netherlands (ECN) where he works in the Intelligent Energy Grids program as Researcher and Project coordinator.

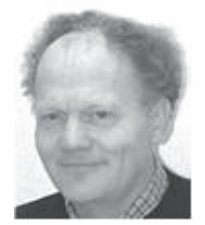

René Kamphuis holds a $\mathrm{PhD}$ in chemical physics. He is currently employed at the department Efficiency \& Infrastructure of the Energy research Centre of the Netherlands (ECN) where he works in the Intelligent Energy Grids program. He headed several projects integrating ICT and Energy via autonomous agent software technology and initiated and participated in the EU CRISP-project and Integral-project. He is the Dutch country expert in IEA-DSM programme projects (e.g. on Demand Response Resources). 